\title{
EVOLUÇÃO DO AUXILIAR VERBAL TEMPO-ASPECTUAL TA - DA LÍNGUA CLÁSSICA À MODERNA
}

Shirlei Lica Ichisato Hashimoto

RESUMO: Na língua clássica japonesa havia seis auxiliares verbais tempoaspectuais: $K i$ e Keri (auxiliares verbais de passado) e $T s u, N u$, Tari e $R i$ (auxiliares verbais de aspecto perfectivo).

No processo de evolução da língua clássica para a língua moderna, esses dois grupos distintos de auxiliares verbais reduziram-se a um único auxiliar verbal $T a$, que se originou do auxiliar verbal perfectivo Tari da língua clássica.

O nosso objetivo é estudar a evolução do Tari desde a língua clássica até a moderna, demonstrando as mudanças de enfoque que foram sendo privilegiadas no decorrer de sua evolução.

ABSTRACT: In the classical Japanese language there were six tense-aspectual verbal auxiliaries: $K i$ and $K e r i$ (past tense verbal auxiliaries) and Tsu, Nu, Tari and $R i$ (perfective aspect verbal auxiliaries).

In the classical Japanese language evolution process to the modern language, these two distinct groups of verbal auxiliaries were reduced to only one verbal auxiliary $\mathrm{Ta}$, originated from the classical languages perfective verbal auxiliary Tari.

This study aims to study the Tari's evolution since the classical language until the modern, demonstraining the variation of points of view during this evolution.

KEYWORDS: Tense, Aspect, Evolution, Verbal auxiliary Tari, Verbal auxiliary Ta.

PALAVRAS-CHAVE: Tempo, Aspecto, Evolução, Auxiliar verbal Tari, Auxiliar verbal $T a$. 
$\mathrm{Na}$ língua clássica japonesa havia seis auxiliares verbais tempo-aspectuais: $K i$, Keri (auxiliar verbal de tempo passado) e $T s u, N u$, Tari, $R i$ (auxiliares verbais de aspecto perfectivo).

O auxiliar verbal Ta origina-se do Tari, mas a existência de seis auxiliares verbais para indicar as noções tempo-aspectuais nos levou a refletir sobre a evolução do sistema temporal da língua japonesa clássica à moderna.

Neste artigo propomos estudar a evolução do auxiliar verbal Tari até a ocorrência do auxiliar verbal $T a$ da língua moderna e demonstrar diacronicamente as mudanças de enfoque na expressão do Tempo.

\section{Tempo e Aspecto}

O tempo lingüístico possui dois sistemas temporais: um relacionado diretamente ao momento da enunciação ${ }^{1}$ e outro ordenado em função de momentos de referência instalados no enunciado. $\mathrm{O}$ meio de tornar inteligíveis os marcadores do tempo lingüístico é ancorá-los numa divisão do tempo cronológico².

Tempo lingüístico e tempo cronológico são duas interpretações da noção semântica do Tempo e que juntos instauram uma macro-estrutura que permite aos homens moverem-se no Tempo.

Cada língua organiza e classifica a noção semântica de Tempo ${ }^{3}$ de acordo com a sua apreensão e visão de mundo, o que nos faz pressupor que uma mesma noção pode ter diferentes representações lingüísticas de uma língua para outra.

A noção semântica do Tempo manifesta-se na língua, notadamente, através de seus verbos. Em se tratando de verbos, há de se considerar duas categorias lingüísticas intrinsecamente relacionadas com a expressão temporal: tempo e aspecto.

Segundo Comrie (1976:1-13), o "tempo gramatical (tense) relaciona o tempo de uma dada situação ${ }^{4}$ a um outro tempo, geralmente o momento da fala. (...) É o concei-

1. A Teoria da Enunciação de Benveniste diz que a enunciação é a instância do ego-hic-nunc (eu, aqui, agora). Essa instância subdivide-se nas categorias de Pessoa, Tempo e Espaço.

2. O tempo cronológico está intimamente relacionado ao conhecimento do ritmo temporal, bem como do princípio da causalidade (causa-efeito) e da sucessão regular dos eventos naturais: alternância do dia e da noite, fases da lua, movimento das marés, estações climáticas etc. O calendário é, assim, fruto de um esforço para objetivar o tempo cronológico. Ele permite aos homens transferir seu referencial na linha do tempo e falar de outras era, sem o perigo de se tornar incoerente.

3. Adotamos Tempo (letra maiúscula) para nos referirmos ao conceito e tempo (letra minúscula) para indicar que estamos nos referindo à sua expressão lingüística (gramatical) na língua.

4. O termo "situação" é usado num sentido amplo, isto é, pode referir-se tanto a um "processo" (por exemplo: florescer), quanto a um "estado" (observar) ou a um "evento" (fechar). Processos são situações dinâmicas que se estendem no tempo (crescer). Estados são processos que se estendem no tempo, mas diferem destes por não sofrerem mudanças durante o período de sua existência (continuar). Eventos são situações dinâmicas momentâneas que não se estendem no tempo (cair). 
to semântico de uma referência temporal (absoluto ou relativo) que pode ser gramaticalizada na língua, isto é, a língua pode ter uma categoria gramatical que expressa referências temporais (...). Aspecto são diferentes maneiras de representar a constituição temporal interna de uma situação"

De acordo com essa definição, o tempo verbal pode ser determinado em relação ao momento da enunciação (momento da fala), embora nem sempre esta relação seja obrigatória, uma vez que distingue o tempo em "absoluto" - orientado pelo momento da fala - e "relativo" - em relação a um outro tempo instaurado no contexto - Os tempos absolutos apresentam um panorama das situações, localizando-as como anterior (passado), simultânea (presente) e posterior (futuro) ao momento da produção do texto ou no ato de dizer. Os tempos relativos ordenam as situações em sua sucessão cronológica no mundo real, uma vez que instauram pontos de referência para organizar as relações de simultaneidade ou posterioridade entre dois pontos da linha de tempo, um dos quais podendo vir a ser o momento da enunciação. Isso significa que o Tempo também pode ser analisado através de um outro ponto de vista que não o da "dêixis", já que o "tempo relativo" não se limita apenas a relacionar o acontecimento ao momento da fala, mas também faz a ligação deste com algum outro acontecimento, reforçando a idéia de seqüencialidade dos fatos.

O aspecto focaliza a "constituição temporal interna de uma situação" Refere-se à maneira como o tempo decorrido dentro dos limites da situação é percebido pelo falante. Segundo Castilho (1968:14), a palavra "aspecto" encerra a raiz spek (ver), o que caracteriza a ênfase na objetividade, uma característica importante da noção aspectual. Costa (1997:21) ressalta que o aspecto independe do ponto dêitico da enunciação, visto que centra o tempo "no fato" e não o fato "no tempo" Essa perspectiva centraliza o ponto de vista nas "situações"

A oposição aspectual básica das situações é estabelecida na constatação de que a situação pode ou não ter a sua constituição interna considerada pelo falante. Temos, assim, dois pontos de vista que, lingüisticamente, denominamos "aspecto imperfectivo" e "aspecto perfectivo"

Comrie (1976:4) diz que “(...) o aspecto imperfectivo focaliza a situação de dentro para fora e como tal está intrinsecamente relacionado à estrutura interna da situação, uma vez que pode tanto voltar o olhar para o início, ou para o término da situação e de fato é igualmente apropriado se a situação permanece por todo o tempo, sem nenhuma referência quanto ao seu início ou término. (...) $\mathrm{O}$ aspecto perfectivo indica a situação vista de fora para dentro, sem necessariamente distinguir algo da estrutura interna da situação"

$\mathrm{O}$ aspecto imperfectivo faz com que visualizemos o desenrolar da situação de tal modo que apenas a fração de tempo compreendida entre o limite inicial e o limite final do fato enunciado estivesse em foco. Compreende, assim, as noções semânticas como a duração, continuidade e progressividade.

No aspecto perfectivo, todas as partes da situação são apresentadas como um todo, em sua globalidade, o que significa dizer que o todo da situação é apresentado 
com começo, meio e fim conjuntamente, sem a tentativa de dividir em fases de desenvolvimento. Por essa característica, o aspecto perfectivo normalmente é confundido com a noção temporal de passado.

Observemos o seguinte exemplo:

Maria estava preparando um bolo de chocolate, quando tocou o telefone.

$\mathrm{Na}$ frase acima, "estava preparando" representa a constituição interna da situação "preparar", em que o início e o fim não são determinados, uma vez que o foco recai na duração da situação. A segunda parte, "tocou" introduz uma nova situação, só que desta vez sem considerar sua constituição interna, pois o ato de "tocar" é percebido pelo falante como situação observada como um todo.

Costa (1997:33) observa que aí se estabelece uma confusão entre "referência ao ponto terminal de um fato" e "referência ao fato enunciado como acabado"

$O$ fato acabado tem ênfase principalmente no fim de uma situação, porém esse fim está relacionado ao ponto dêitico da enunciação. Daí constatar que a noção de acabado tem mais relação com "tempo" do que "aspecto" Já o perfectivo refere-se ao fato como um todo, como completo, com princípio, meio e fim, sem enfatizar qualquer das partes constitutivas do seu tempo interno, quer a parte final, quer qualquer outra. Todo perfectivo implica necessariamente que o fato que se expressa seja visto como um todo no qual se inclui o ponto terminal, mas isso não implica que todo perfectivo refere-se a fatos acabados, porque, se assim fosse, o perfectivo seria privativo do tempo passado.

O falante, ao perceber a situação em sua globalidade (perfectivo) ou ater-se aos detalhes que envolvem o desenvolvimento da situação (imperfectivo), acaba por extrapolar os limites das divisões temporais, o que lhe permite expressar objetivamente seu ponto de vista em relação às situações que o envolvem.

Além dessas duas noções aspetuais, Comrie (1976:52) observa que há uma outra noção aspectual a ser considerada: o aspecto perfect $t^{5}$. "O aspecto perfect indica que uma situação do passado continua relevante no presente"

$\mathrm{O}$ aspecto perfect refere-se, portanto, a uma situação que se inicia no passado e cujo resultado é percebido no presente:

Ele quebrou a perna no acidente e desde então tem lido muitos livros.

$\mathrm{Na}$ frase acima, "quebrar" é um processo acabado que ultrapassou seu ponto final, transformando-o em estado e "tem lido" coloca em evidência o presente contínuo de uma situação ocorrida anteriormente.

5. Adotamos o termo perfect em inglês, conforme Comrie (1976:52), para não confundi-lo com o termo "perfeito" utilizado na língua portuguesa. 
Segundo Comrie (1976:52), a diferença entre o perfectivo e o perfect é que este é um tipo de aspecto que faz a ligação de algo do passado com o presente, enquanto aquele não implica esse tipo de relação. Citamos o exemplo mencionado em Comrie, tendo o cuidado de fazer a tradução literal para não perder a nuance que esse tipo de construção contém:
a) I have lost (perfect) my penknife
(Eu tenho perdido meu canivete)
b) I lost (non-perfect) my penknife (Eu perdi meu canivete)

O exemplo (a) implica que o canivete ainda está perdido, enquanto que o (b) implica que a perda é percebida como um fato consumado. O perfect liga dois pontos na linha do tempo: passado e presente e, por compartilhar tanto do passado quanto do presente, há uma polêmica em se considerar ou não o perfect como um traço aspectual. No entanto, Comrie observa que, apesar da ligação temporal passado e presente existente na noção de perfect, este pode ser considerado um tipo aspectual, desde que entendamos o perfect como indicador de "estado" presente de uma "situação" passada.

Podemos concluir que o tempo e o aspecto são recursos lingüísticos que nos disponibilizam expressar as diferentes maneiras de focar uma situação.

\section{Auxiliar verbal tempo-aspectual da língua japonesa}

Na língua clássica japonesa havia uma nítida distinção de uso entre os seis auxiliares verbais tempo-aspectuais: Ki, Keri (auxiliar verbal de tempo passado) e $T s u, N u, T a r i, R i$ (auxiliares verbais de aspecto perfectivo). Esta tem sido a classificação encontrada nas gramáticas escolares.

No processo de evolução da língua clássica para a língua moderna japonesa, esses dois grupos distintos de auxiliares verbais reduziram-se a um único auxiliar verbal $T a$. Essa diversidade existente na língua clássica leva-nos a crer que o recorte temporal no período clássico era sistematizado de modo diferente ao do período moderno.

Há dois pontos de vista para explicar o uso do auxiliar verbal $T a$ na língua moderna: um defende que, apesar da simplificação da forma, ele possui múltiplos significados (pragmáticos) provenientes dos auxiliares verbais de passado e perfectivo da língua clássica; o outro defende que a simplificação apenas enfatizou o caráter aspectual (semântico) da língua japonesa.

A atual polêmica sobre o sistema temporal da língua japonesa origina-se da interpretação do auxiliar verbal $T a$. Há três propostas e cada qual interpreta esse auxiliar verbal como sendo, respectivamente, indicador de "tempo passado e aspecto perfectivo", de "aspecto perfectivo" e de "tempo relativo" 
Diante dessa polêmica, percebemos a necessidade de fazer um estudo diacrônico do auxiliar verbal tempo-aspectual $T a$, percorrendo o seu processo de evolução desde a língua clássica até a moderna.

\section{Estudo diacrônico - evolução do auxiliar verbal Ta}

\section{- Considerações gerais -}

A divisão histórica adotada nos estudos lingüísticos difere das adotadas nos estudos históricos, literários e culturais, uma vez que possui certas particularidades. Adotamos a sugestão de Satô (1986) e consideraremos três grandes divisões: Antigüidade (Kodai), Medievo ${ }^{6}$ (Chûsei) e Moderno ${ }^{7}$ (Kindai):

$$
\begin{array}{ll}
\text { Antigüidade } \rightarrow \text { períodos: } & \text { Nara }(712 \sim 793) \sim \text { Heian }(794 \sim 1085) \\
\text { Medievo } \rightarrow & \text { Insei }(1086 \sim 1186) \sim \text { Muromachi }(1392 \sim 1573) \\
\text { Moderno } \rightarrow & \text { Edo }(1630 \sim 1868) \sim \text { Meiji }(1868 \sim 1912)
\end{array}
$$

Em linhas gerais, podemos dividir a língua japonesa em clássica e moderna. Considera-se o período Muromachi (1392 1573) como sendo o período de transição da língua clássica para a moderna. Neste período a língua já apresenta muitos elementos encontrados na língua moderna. Cabe observar que as gramáticas de língua clássica adotadas nas escolas têm como referência a língua japonesa do período Heian.

Nosso estudo não abrangerá o período Moderno, uma vez que o objetivo é fazer um breve histórico da evolução do auxiliar verbal tempo-aspectual Tari, da língua clássica, até o auxiliar verbal $T a$, da língua moderna.

O primeiro registro do Ta encontra-se nas Narrativas de Heike (Heike monogatari, 1222) no final do período Kamakura e seu emprego firmou-se no final do período Muromachi (meados do século XVI).

Hida (1972) nos fez observar a necessidade de demarcar os períodos em que os auxiliares verbais eram predominantemente utilizados na língua falada ou na escrita, uma vez que nem sempre compartilham o mesmo período. Outro ponto importante a ser considerado num estudo histórico é a relação existente entre os fatos lingüísticos e os gêneros das obras literárias (poesia, narrativas, diários, ensaios etc).

6. Adotamos o termo Medievo para não associá-lo à concepção de Idade Média da história Ocidental.

7. O período Moderno (kindai) não deve ser confundido com o período Contemporâneo (gendai) que engloba a língua moderna japonesa praticada nos dias atuais. 


\section{Evolução do auxiliar verbal Tari da língua clássica ao Ta da língua moderna.}

\section{Etimologia}

Há duas interpretações sobre a origem do Tari.

A primeira diz que o Tari origina-se da combinação entre a partícula de ligação $T e$ e o predicador de ação ${ }^{8}$ irregular Ari (ter, haver, existir). No período Nara a seqüência de duas vogais era evitada, o que explica a queda da vogal /e/ em combinações do tipo Te + Ari, formando o auxiliar verbal Tari.

A segunda diz que o $T e$ origina-se da flexão adverbial (ren yôkei) do auxiliar verbal perfectivo Tsu que passou a exercer a função de "partícula" que liga o predicador de ação principal e o predicador Ari. Yamada (1908) é um dos que defendem essa interpretação.

Kasuga (1964) observa, a partir de um estudo minucioso sobre a ocorrência do Tari no Man'yôshû (Antologia poética das dez mil folhas, 759) que nessa obra ainda se mantém a etimologia original $T e+A r i$ sem a queda da vogal /e/. Segundo o autor, isso implica que havia uma intenção de enfatizar os significados do auxiliar verbal perfectivo Tsu e do predicador Ari (existir) e que a combinação fonética podia, nesses casos, ser ignorada para promover um efeito de sentido. Isso também nos revela que as mudanças fonéticas aplicadas aos predicadores e auxiliares verbais ou mesmo entre os auxiliares verbais ocorreram gradativamente. Diante disso, adotamos a posição de Yamada (1918).

Flexão do auxiliar verbal Tari e Ta

$\begin{array}{llc}\text { Forma básica: } & \text { Tari } & \text { Ta } \\ \text { Mizenkei (situação não realizada) } & \text { Tara } & \text { Tara } \\ \text { Ren'yôkei (adverbial) } & \text { Tari } & - \\ \text { Shûshikei (terminativa) } & \text { Tari } & \text { Ta } \\ \text { Rentaikei (atributiva) } & \text { Taru } & \text { Ta } \\ \text { Izenkei (condicional) } & \text { Tare } & \text { Tara } \\ \text { Meireikei (imperativa) } & \text { Tare } & -\end{array}$

8. O termo predicador de ação (dôshi) segue a proposta de terminologia adotada pelo Grupo Interinstitucional de Estudos da Língua Japonesa. 


\section{Evolução do auxiliar verbal Tari ao Ta}

A introdução de ideogramas e a leitura de textos religiosos, literários e políticos da China criaram a necessidade de se estabelecerem regras de interpretação e readaptação à língua japonesa falada, o que promoveu a conscientização das diferenças lingüísticas existentes entre a língua chinesa e a japonesa.

A principal característica dos auxiliares verbais do período Nara é a "autonomia" de seus vocábulos. É importante ressaltar que as classes gramaticais desse período nem sempre correspondem às dos períodos posteriores.

Dentre esses elementos lingüísticos, destacamos o auxiliar verbal perfectivo Tari que se originou de um predicador de ação (dôshi) chinês e, por isso, nesse período, ainda tinham uma autonomia sintático-semântica maior que nos períodos posteriores. Pode-se dizer que, no período Nara, esses elementos eram utilizados como predicadores de ação e também como auxiliares verbais.

Segundo Yoshida (1972), a explicação para a autonomia dos elementos lingüísticos desse período reside no fato de esses elementos serem as primeiras adaptações do universo lingüístico chinês para o japonês. Havia a necessidade de se inserir a leitura japonesa em grande parte das palavras herdadas do chinês, mas, na prática, não havia ainda uma nítida desvinculação entre sua carga semântica e sua leitura chinesa.

No período Heian, os auxiliares verbais que tinham autonomia no período anterior passam a sofrer mudanças, tornando-se mais dependentes dos vocábulos que os antecedem. $\mathrm{O}$ encadeamento (aglutinação) dos auxiliares verbais propiciou expressar significados mais precisos. Essa adaptação dos auxiliares verbais para pormenorizar as sutilezas que se desejava transmitir foi amplamente desenvolvida nos gêneros literários desse período.

No período Medievo, os vocábulos perdem a "autonomia" e passam a ter fortes tendências aglutinantes. A aglutinação de vários auxiliares verbais forma encadeamentos longos em sequiências de idéias, que estabeleciam relações complexas de significados e, ao mesmo tempo, permitiam expressar com maior sutileza e singularidade os sentimentos e as emoções dos japoneses.

Durante esse período, o significado e o uso dos auxiliares verbais são explorados ao máximo tanto na poesia quanto nas narrativas.

A língua praticada no período Heian, centralizada na corte e na literatura feminina, sofre mudanças com a nova classe social emergente constituída por guerreiros e monges. Este período é marcado por intensas transformações sociais, políticas e culturais que se refletiram na língua, promovendo mudanças.

$\mathrm{O}$ mundo das letras que no período anterior refletia a cultura aristocrática passa a refletir a cultura dos guerreiros e dos monges, refletindo essa instabilidade na língua. De um lado, há a preservação dos auxiliares do período anterior, mas, de outro, há o surgimento de novos auxiliares verbais, principalmente os de respeito, modéstia e humildade. 
Refletindo o distanciamento entre a língua escrita e a falada, os auxiliares verbais também se dividem em dois grupos: os auxiliares verbais da escrita e os da língua falada. Ocorrem também mudanças no sistema lexical devido ao aumento de auxiliares verbais compostos, como modificações morfológicas e fonéticas para se adaptarem às novas combinações.

Há, também, a consolidação da classe dos advérbios, que passará a ter uma função importante no sistema temporal.

Os auxiliares verbais tempo-aspectuais $\mathrm{Ki}, \mathrm{Keri}, \mathrm{Tsu}, \mathrm{Nu}$, Tari, Ri começam a perder o seu esplendor de outrora. O $R i$ cai em desuso na língua escrita e falada, enquanto que o Tari passa a abarcar as funções dos outros auxiliares.

Após os conflitos e mudanças sociais ocorridas no período anterior, estabelece-se uma sociedade feudal. As diferenças sociais relacionadas à profissão, sexo, idade começam a se refletir na linguagem, diversificando o uso das expressões de tratamento 9 .

Os auxiliares verbais também se tornam mais complexos. Ocorre uma sistematização dos auxiliares verbais de polidez, a fim de abranger as diversas classes sociais.

A oposição entre a cultura do leste (Kyôto e Ôsaka) e a do oeste (Tóquio) enfatiza a existência de dialetos. Este período foi um período em que a linguagem falada e a escrita se tornam nitidamente distintas, ocorrendo também o uso diferenciado dos auxiliares verbais. Dentre os auxiliares verbais de passado e perfectivo da língua clássica japonesa, somente o Ta passa a ser utilizado na língua falada. Na língua escrita apenas algumas flexões do $\mathrm{Ki}, \mathrm{Keri}, \mathrm{Tsu}, \mathrm{Nu}$, Tari são utilizadas de modo extremamente restrito.

$\mathrm{O}$ auxiliar verbal Tari sofreu mudanças de significado durante o seu longo percurso até a simplificação na forma $T a$ :

\section{Aspecto Perfect}

1) Indica a constatação de que a situação existe até o presente. Também indica a constatação de que um estado ou uma situação permanece até o presente. Equivale ao que Comrie (1976), citado anteriormente, denomina como aspecto perfect.

\section{Aspecto Perfectivo}

2) Indica que uma situação é percebida como um todo, sem a tentativa de dividila em fases de desenvolvimento (aspecto perfectivo). Muitas vezes, pelo contexto, pode referir-se a algo concluído e indicar que a situação já ocorreu no tempo passado.

\section{Aspecto perfectivo e Tempo passado}

3) A nível pragmático, o contexto indica tempo passado. A oração principal normalmente determina a situação em relação ao momento da fala (tempo) e as subordi-

9. SUZUKI, Tae (1995) desenvolve um estudo sobre "As expressões de tratamento na língua japonesa". 
nadas e coordenadas relacionam-se à oração principal desenvolvendo a aspectualidade das situações.

Em obras tais como o Kojiki (Relato de fatos antigos, 712) e o Nihonshoki (Crônicas do Japão, 720) não há nenhum registro de Teari ou Tari. Somente no Man'yôsh û (Antologia poética das dez mil folhas, 759) é que encontramos alguns exemplos de Tari e em sua expressão original $(T e+A r i)$ conforme citado na etimologia.

machik a le n i wag a surutsukiw a imogak i rumikasanoyaman i kom r i i e a rike $r$ i

「待ちかてにわがする月 は妹が着る三笠の山に隠りてありけり」

(Man'yôshû 6-987,759)

"A lua me faz lembrar de minha esposa que, na distante montanha Mikasa, com seu chapéu de bambu está a me aguardar..."

(Antologia poética das dez mil folhas 6-987,759)

O Tari é encontrado nos textos de estilo japonês (wabun) do período Heian. Segundo Yamada (1918), no período Nara os auxiliares verbais comumente encontrados com o Tari são o auxiliar verbal de negação $Z u$ (Tarizu), o auxiliar verbal de tempo passado Keri (Tarikeri) e o auxiliar verbal de suposição Ramu (Taramu).

Okamoto (1985) observa que, nesse período, a conscientização etimológica ainda era muito forte e, por isso, encontramos na escrita alguns exemplos de Teari, apesar de que na língua falada pressupõe-se que já se pronunciava Tari.

Nos textos de estilo kana, como por exemplo, Narrativas do cortador de bambu, escrito em 901 (Taketori monogatari) há no diálogo o uso de quase todas as flexões, com exceção da flexão imperativa (meireikei).

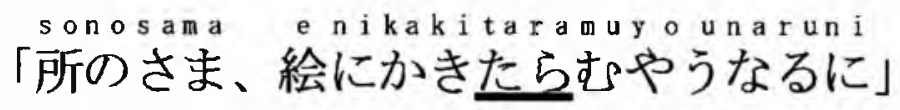

(Genji monogatari, 1008)

"A cena deste lugar parece ser exatamente igual ao que está desenhado"

(Narrativas de Genji, 1008)

$\mathrm{Na}$ narração não encontramos as flexões de situação não realizada (mizenkei) e imperativa (meireikei). $\mathrm{O}$ único auxiliar verbal que acompanha a flexão adverbial (ren yôkei) é o de passado Keri.

Hida (1972) observa que, pelo tipo de auxiliar verbal que acompanha o Tari, pode-se admitir que o uso deste era maior na língua falada e por isso era mais utilizado nos diálogos dentro das narrativas.

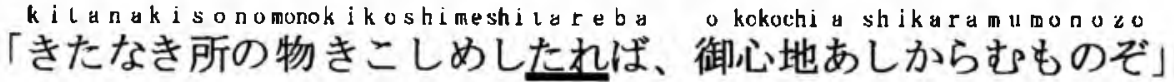

(Taketori monogatari, 901) 
"Você se sente mal, por ter comido coisas do lugar sujo (mundo dos homens)"

No período Kamakura, surge também o uso encadeado da flexão terminativa (shûshikei) ' ...Tari....Tari...10

$$
\begin{array}{ccc}
\text { ha } i \text { tari nogo u tari chirihiro } i \\
\text { 「掃いたり、拭うたり、塵拾ひ....」 }
\end{array}
$$

(Heike monogatari, 1222)

"Varre, passa o pano, recolhe a sujeira...."

(Narrativas de Heike, 1222)

No final do período Heian, encontra-se alguns exemplos em que as flexões: adverbial (ren yôkei) e terminativa (shûshikei), ambas na forma Tari, perdem a sílaba final - $R i$ e passam a ser utilizadas como $T a$. O primeiro registro do $T a$ encontra-se nas Narrativas de Heike, 1222, no final do período Kamakura.

$$
\begin{aligned}
& \text { hashi } 0 \text { hi i tazo a y amachisuna } \\
& \text { 「橋を引いたぞ、あやまちすな」 }
\end{aligned}
$$

(Heike monogatari, 1222)

"Os inimigos tiraram a tábua da ponte, cuidado, não empurrem"

(Narrativas de Heike, 1222)

Este uso do $T a$ é considerado o ancestral do $T a$ da língua moderna japonesa.

Segundo Hashimoto (1973), o uso simplificado do Ta ocorreu, inicialmente, na região de Kyôto, Ôsaka e adjacências (Kansai) para depois estender-se às demais regiões. Verifica-se também que as flexões adverbial (ren yôkei) e condicional (izenkei) caem em desuso, enquanto que as flexões terminativa (shûshikei) e atributiva (rentaikei) tornam-se cada vez mais utilizadas. Outro dado importante é que o $T a$, que antes enfatizava o significado aspectual perfect, passa a incorporar um novo significado: a ênfase no aspecto perfectivo e, conseqüentemente, no tempo passado.

Isso pode ser verificado, principalmente, após o período Muromachi:

$$
\begin{aligned}
& \text { chi enolakelamonomokonohiloninabukolowaorinakaしıa } \\
& \text { 「智恵のたけたものもこの人に並ぶことはおりなかった」 }
\end{aligned}
$$

(Isoppo monogatari, Amakusa-ban, 1593)

"Até mesmo uma pessoa considerada erudita, não ficou ao lado desta pessoa." (Narrativas de Esopo, edição Amakusa, 1593)

10. É este uso que encontramos atualmente em expressões do tipo: Ittari Kitari (ir e vir) e Mitari e Kiitari (ver e ouvir). 
O Ta utilizado na flexão terminativa (final da frase), no exemplo acima, ilustra o uso do Ta com o sentido de passado (orinakatta $=$ não ficou). Convém observar que a flexão atributiva (rentaikei) mantém o seu significado aspectual (Chie no take ta mono $=$ pessoa considerada erudita).

Se na linguagem falada o uso do Ta já era freqüente, na escrita, principalmente nas narrativas do período Muromachi, as flexões terminativas e atributivas Tari e Taru também vão sendo gradativamente substituídas pelo $T a$.

Segundo Yuzawa (1985:172 174), no período Muromachi, o uso da flexão de situação não realizada (mizenkei) torna-se restrito à combinação Tara $+b a$ que expressa suposição. Após o período Muromachi, a flexão imperativa (meireikei) deixa de ser utilizada na linguagem escrita. Nos diálogos, encontramos somente as combinações Tarikeri, Tarunari ou Tanari. Segundo Hida (1972), tanto o uso do Tari como o do Taru eram restritos a textos religiosos doutrinários e, por isso, restritos à linguagem masculina. Por outro lado, o Ta era utilizado tanto por homens quanto pelas mulheres. Nas edições Amakusa, das Narrativas de Esopo (Isoppo monogatari,1592) encontramos o uso predominante do $T a$, na flexão terminativa e atributiva.

Uma tendência que se verifica desde o período Heian e que se intensifica após o período Muromachi são as mudanças fonéticas (eufonia) verificadas em determinados vocábulos que antecedem esse auxiliar verbal. Em alguns casos, o $T a$ se pronuncia $D a$.

\section{Conclusão}

A evolução do sistema temporal Tari pode ser esquematizada da seguinte forma:

\begin{tabular}{|cl|}
\hline Teari & aspecto perfect \\
$\downarrow$ & \\
Tari & aspecto perfect e perfectivo \\
$\downarrow$ & \\
Ta & aspecto perfectivo e tempo passado \\
\hline
\end{tabular}

Como se pode observar, a forma Tari possuía inicialmente o sentido de aspecto perfect e, gradativamente, passou a indicar aspecto perfectivo e, por extensão, em alguns contextos, passou a indicar tempo passado. Segundo Suzuki (1993), o auxiliar verbal Tari, que originou o Ta da língua moderna japonesa, sobreviveu porque, além de indicar o aspecto perfectivo, pode também indicar o aspecto perfect e o tempo passado, o que constitui uma economia lingüística.

Segundo Yamaguchi (1989), dentre os seis auxiliares verbais tempo-aspectuais da língua clássica (Ki, Keri, Tsu, Nu, Tari, Ri), o Tari era o único que tinha as condições morfológicas (não tinham restrições de uso), sintáticas (as flexões terminativa e atributiva eram utilizadas tanto na escrita quanto na fala) e semânticas (possuem tanto o sentido de conclusão de uma situação como também podem indicar a relação existente entre uma conclusão e uma situação do presente) para se adequar às mudanças lingüísticas. 
O auxiliar verbal tempo-aspectual $T a$ está sofrendo o fenômeno de "gramaticalização", ou seja, distancia-se de sua origem etimológica (auxiliar verbal) e passa a ser um morfema tempo-aspectual.

\section{Bibliografia}

CASTILHO, Ataliba T. de. Introdução ao estudo do aspecto verbal na língua portuguesa. Marília: Coleção de teses, 1968.

COMRIE, B. Aspect. London, NY, Melbourne: Cambridge University Press. 1976.

COSTA, Sônia Bastos Borba. O aspecto em português. São Paulo: Contexto, 1997.

HASHIMOTO, Shinkichi. Joshi jodôshino kenkyû (Estudos sobre as partículas e os auxiliares verbais). (1 ${ }^{\text {a }}$. Edição 1969). Tóquio: Iwanami, 1973.

HIDA, Yoshifune. Kanryô no jodôshi (auxiliar verbal perfectivo) In: Hinshibetsu nihonbunpô kôsa (Coletânea da gramática japonesa por classe gramatical). Volume II. Tóquio: Meiji shoin, 1972. Páginas $26 \sim 67$.

KASUGA, Kazuo. Jodôshi keri. (Auxiliar verbal keri) In: Gengo to Bungei (Língua e Literatura). Tóquio: volume 33, 1964.

OKAMOTO, Isao. Kako, kanryô no jodôshi (Auxiliares verbais de passado e perfectivo). In: SUZUKI, Kazuhiro e HAYASHI, Ôki. Kenkyû shiryô nihon bunpô (Estudos sobre a gramática japonesa). Tóquio: Meiji shoin. Volume 7.1985. Páginas $48 \sim 63$.

SATÔ, Kiyoji. Kokugoshi (História da língua japonesa). Tóquio: Ôfûsha. 2 volumes, $2^{\text {a. }}$ Edição. 1986.

SUZUKI, Tai. Jikan hyôgen no hensei (As mudanças na expressão do tempo) In: Revista Gengo (Língua), volume 22-2. Tóquio: Taishûkan Shoten, pp 60-67, 1993.

YAMADA, Yoshio. Narachô bunpô shi (Gramática histórica do período Nara). Tóquio: Meiji Shôin. 1918.

YAMAGUCHI, Akiho. Kokugo no ronri - Kodai kara kindaigo e (A lógica da língua japonesa - da língua clássica à moderna ). Tóquio:Universidade de Tóquio, 1989.

YUZAWA, Kôkichirô. Bungo Bunpô Shôsetsu (Gramática da Língua Clássica).

Tóquio:Yûbun Shoin, 1985.

YOSHIDA, Kanehiko. Hinshibetsu nihon bunpô kôsa (Estudo da gramática japonesa por classe gramatical). Tóquio: Meiji Shoin. Volume I. 1972. Páginas $26 \sim 67$. 
